Check for updates

Cite this: Chem. Commun., 2018, 54,8104

Received 24th May 2018,

Accepted 28th June 2018

DOI: $10.1039 / \mathrm{c} 8 \mathrm{cc} 04152 \mathrm{k}$

rsc.li/chemcomm

\section{Sustainable hydrophobic terpene-based eutectic solvents for the extraction and separation of metals $\dagger$}

\author{
Nicolas Schaeffer, (D) a Mónia A. R. Martins, (D) abc Catarina M. S. S. Neves, (D) a \\ Simão P. Pinho (iD ${ }^{\text {bc }}$ and João A. P. Coutinho (D)*a
}

\begin{abstract}
Sustainable hydrophobic eutectic solvents, composed of low-priced and biodegradable terpenes and fatty acids, were used for the extraction and separation of $\mathrm{Cu}(\mathrm{II})$ from other transition metals in mildly acidic solutions. Multiple parameters were evaluated for metal extraction and the hydrophobic eutectic solvent was successfully recovered and reused.
\end{abstract}

Metals represent an inherent source of both economic value and toxicity, with their consumption projected to increase in line with global economic standards. ${ }^{1}$ However, metals are finite commodities; the imbalance between demand and supply risk led the European Union to identify several metals as critical for its continued economic growth. ${ }^{2}$ Hydrometallurgy is often favoured by industry for the extraction and separation of metals due to its ability to recover them from a variety of challenging sources, allowing the use of low process temperatures and the recycling of reagents. An important stage of any hydrometallurgical process is solvent extraction, in which metals selectively partition between mutually immiscible liquid phases, usually consisting of an aqueous acidic solution and a low-polarity solvent. ${ }^{3}$ In recent years, notable advances in the development of metal extraction systems were made, from traditional solvent extraction, using extractants diluted in common organic solvents, to more recent developments based on ionic liquids and deep eutectic solvents (DES) mediated extraction. ${ }^{3,4}$ For any solvent to be eligible for use in solvent extraction, it must possess low water solubility, low vapour pressure, simple synthesis, low cost, high selectivity towards the target solute, high solvent loading, low viscosity and low toxicity. In this context, hydrophobic eutectic

\footnotetext{
${ }^{a}$ CICECO, Department of Chemistry, University of Aveiro, Portugal. E-mail: jcoutinho@ua.pt

${ }^{b}$ Associate Laboratory LSRE-LCM, Department of Chemical and Biological Technology, Polytechnic Institute of Bragança, Portugal

${ }^{c}$ Mountain Research Center - CIMO, Polytechnic Institute of Bragança, Portugal

$\dagger$ Electronic supplementary information (ESI) available: Detailed experimental procedure; UV-vis spectra of aqueous phase before and after extraction; thermophysical properties of HES; ${ }^{1} \mathrm{H}$-NMR spectra of aqueous phase; extraction efficiency of $\mathrm{Cu}(\mathrm{II})$ over multiple recycling cycles. See DOI: $10.1039 / \mathrm{c} 8 \mathrm{cc} 04152 \mathrm{k}$
}

solvents (HES) have emerged as promising designer solvents for the extraction of varied inorganic ${ }^{5,6}$ and organic solutes. ${ }^{7,8}$ These eutectic mixtures are usually composed of two constituents associated by hydrogen bonding and dispersion forces. These interactions stabilize the HES and lower its melting temperature compared to the melting temperature of the individual pure substances. ${ }^{9}$ HES were used for the recovery of indium and transition metals from chloride media. ${ }^{5,6}$ Although promising, these results were limited by low extraction yields, a lack of selectivity between various transition metals and incomplete recycling of the HES.

Sustainable HES composed of cheap naturally sourced terpenes (such as menthol and thymol) as hydrogen bond acceptor and fatty acids (from caprylic to stearic acids) as hydrogen bond donor were shown to be highly hydrophobic., ${ }^{710}$ Due to the weak hydrogen bonding interactions between the two compounds, such mixtures present only a slight deviation from an ideal solution behaviour, in opposition to what is usually observed for 'deep' eutectic solvents. This lack of dominant hydrogen bond interactions results in a low viscosity HES suitable for solvent extraction applications. ${ }^{10}$ Furthermore, the starting compounds are biodegradable and approved for human consumption by various food and drug agencies, turning the resulting HES of interest for a wide range of industries.

In this work, sustainable HES based on menthol or its aromatic counterpart thymol combined with long chain carboxylic acids $\left(\mathrm{C}_{n} \mathrm{H}_{(2 n+1)} \mathrm{OOH} ; n=8,10,12,14,16,18\right)$ (Fig. $\mathrm{S} 1$ in the ESI $\uparrow$ ), are evaluated for the extraction of $\mathrm{Cu}(\mathrm{II})$ and its separation from other transition metals, namely $\mathrm{Co}(\mathrm{II})$ and Ni(II). The solid-liquid phase diagrams of these HES were previously reported by us along with their physico-chemical properties at compositions close to the eutectic. ${ }^{10}$ These are summarised in Table S1 of the ESI $\dagger$ and serve as the foundation of this communication. The results presented here aim to provide a deeper understanding of metal extraction in HES and provide the basis for the development of other sustainable HES formulations for metal extraction. The mechanisms dictating metal extraction into these HES are determined based on the study of a single metal $\mathrm{CuSO}_{4}$ 

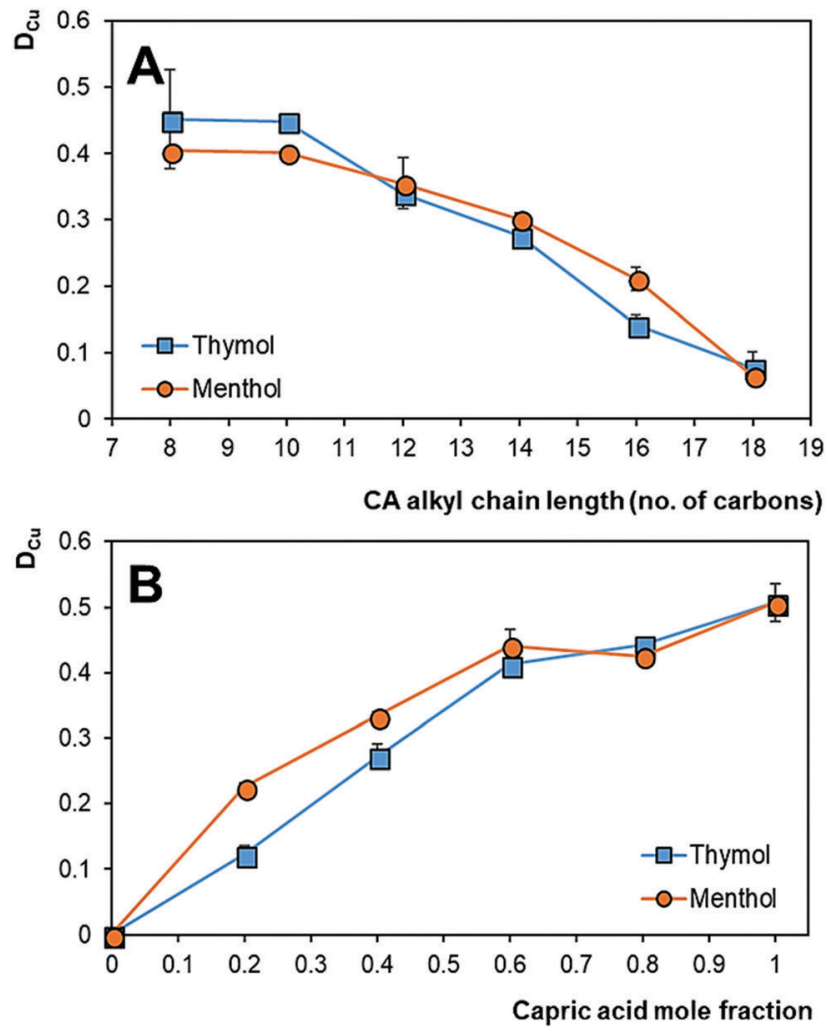

Fig. $1 \mathrm{Cu}(\mathrm{II})$ distribution $\left(D_{\mathrm{Cu}}\right)$ as a function of: (A) the alkyl chain length of the carboxylic acid (CA) at a composition close to the eutectic; $(B)$ the capric acid mole fraction of the HES $\left([\mathrm{Cu}]=0.015 \mathrm{M}, T=50^{\circ} \mathrm{C}, \mathrm{pH}=4.2\right)$.

solution depending on multiple factors including carboxylic acid chain length at a fixed composition, change in composition for a given carboxylic acid, $\mathrm{pH}, \mathrm{Cu}(\mathrm{II})$ concentration and salt additive selection. A detailed description of the experimental methodology is provided in the ESI $\dagger$ including the extraction kinetics ( $c f$. Fig. S2 $\dagger$ ). Whilst studies involving eutectics often focus on a specific molar ratio of their constituents, the complete description of the phase diagram of the studied HES $^{10}$ allows the tuning of the HES composition to maximise metal extraction. As such, $\mathrm{Cu}(\mathrm{II})$ extraction in HES was studied as function of the carboxylic acid selection and the terpene: carboxylic acid molar ratio (Fig. 1). These experiments were performed at $T=50^{\circ} \mathrm{C}$ as not all mixtures studied were liquid at room temperature.

The extraction of $\mathrm{Cu}(\mathrm{II})$, as function of the alkyl chain length of the carboxylic acid at compositions close to the eutectic (Table $\mathrm{S} 1$ in the ESI $\dagger$ ) is presented in Fig. 1A. A steady decrease in the extraction is observed as the carboxylic acid alkyl chain is increased from $n=8$ to $n=18$ in both menthol and thymolbased HES. This trend is in accordance with the decreasing carboxylic acid mole fraction $\left(x_{\mathrm{CA}}\right)$ in the HES with increasing carboxylic acid chain length (Table S1 in the ESI $\dagger$ ). In the case of menthol-based HES, $x_{\mathrm{CA}}$ decreases from 0.40 for caprylic acid to 0.10 for stearic acid. A similar trend is observed for thymolbased HES. Although the highest extraction was obtained using caprylic acid, ${ }^{1} \mathrm{H}-\mathrm{NMR}$ analysis of the aqueous phase after extraction indicated small losses of the carboxylic acid to the aqueous phase. The loss of the caprylic-based HES constituents (close to its eutectic composition) in the absence of $\mathrm{Cu}$ (II) is of the order of $10^{-5}$ mole fraction. ${ }^{10}$ As such, capric acid $(n=10$, $\mathrm{C}_{9} \mathrm{H}_{19} \mathrm{COOH}$ ) was selected for further studies.

For the terpene:capric acid HES, $\mathrm{Cu}$ (II) extraction increases with an increase in $x_{\text {capricacid }}$ until a plateau is reached at $x=[0.6-0.8]$ (Fig. 1B). Further increase in the carboxylic acid content does not result in significantly higher extraction yield suggesting that only a fraction of the acid is involved in metal extraction. This can be partly attributed to the nature of carboxylic acids which are known to form dimers in solution. Fig. 1B clearly shows that the carboxylic acid is responsible for metal extraction, highlighting also the flexibility of the HES and the need for a full evaluation of their phase diagrams. Pure capric acid presented the highest $\mathrm{Cu}(\mathrm{II})$ extraction whilst the pure terpenes dissolved in xylene and cyclohexane for thymol and menthol, respectively, could not extract any $\mathrm{Cu}(\mathrm{II})$. This is unlike previous metal extraction studies using carboxylate HES in which metal extraction was mainly due to the other component of the HES, namely lidocaine and a quaternary ammonium ionic liquid. ${ }^{5,6}$ UV-vis analysis (Fig. S3 in the ESI $\dagger$ ) of the organic phase after extraction confirms that $\mathrm{Cu}$ (II) is extracted in the form of a $\mathrm{Cu}$-capric acid complex with the presence of a large peak at $680 \mathrm{~nm}$ similar to that observed for $\mathrm{Cu}(\text { acetate })_{2}$ hydrate complexes. ${ }^{11}$ Although pure capric acid, in the absence of diluent, displays a marginally greater extraction efficiency than the HES, it was discarded due to the surfactant qualities of pure unbranched carboxylic acids. This surfactant behaviour results in problematic phase separation, a fact not observed during $\mathrm{Cu}$ (II) extraction in HES. A final composition of $x_{\text {capric acid }}=0.7$ was selected since at higher carboxylic mole fraction the HES was no longer liquid at room temperature. ${ }^{10}$ At this HES composition, temperature was not found to have an important influence on $\mathrm{Cu}$ (II) extraction (Fig. S4 in the ESI $\dagger$ ). As such, all further tests were performed at room temperature $\left(20{ }^{\circ} \mathrm{C}\right)$.

Copper extraction by carboxylic acids is a $\mathrm{pH}$ dependent process dictated in part by the acid dissociation constant. ${ }^{12}$ The $\mathrm{p} K_{\mathrm{a}}$ of capric acid is of 4.9. Fig. 2 shows that the extraction of $\mathrm{Cu}(\mathrm{II})$ is inversely proportional to the hydrogen ion concentration. Almost no extraction occurs below pH 3 for both HES tested and increases to a maximum at pH 5.2. Further increase in the $\mathrm{pH}$ is prevented by $\mathrm{Cu}(\mathrm{II})$ hydrolysis. The distribution of $\mathrm{Cu}(\mathrm{II})$ with $\mathrm{pH}$ in HES and capric acid diluted in xylene (Fig. 2) follows a similar behaviour, displaying a sharp increase in extraction after $\mathrm{pH}$ 4.5. Carboxylic acid mediated extraction for a given metal $\left(\mathrm{M}^{n+}\right)$ traditionally follows the deprotonation of the acid to carboxylate and its complexation with the metal cation to form a charge neutral complex. Slope analysis of $\mathrm{Cu}(\mathrm{II})$ extraction in HES, presented in Fig. S5 of the ESI, $\dagger$ indicates that only one deprotonated carboxylate ion coordinates $\mathrm{Cu}$ (II) during extraction. It is speculated that the high extraction $\mathrm{pH}$ also promotes the extraction of intermediate copper sulphate and hydroxide complexes ( $c f$. Table S3 in the ESI $\dagger$ ). Further work is ongoing to clarify the potential extraction mechanisms 


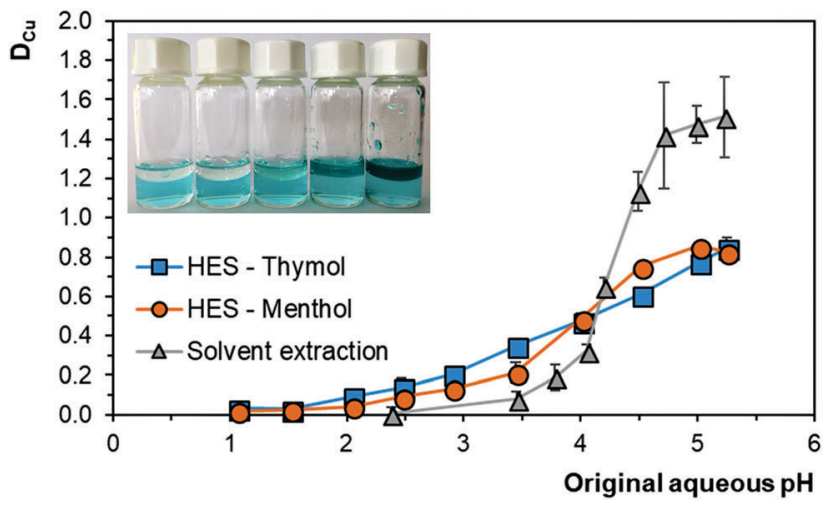

Fig. $2 C u(I)$ distribution $\left(D_{\mathrm{Cu}}\right)$ in HES $\left(x_{\text {capric acid }}=0.7\right)$ and classic solvent extraction with xylene as diluent ([capric acid] $=0.5 \mathrm{M}$ ) as a function of $\mathrm{pH}$ $\left(T=20^{\circ} \mathrm{C}\right)$. Detailed data is provided in Table S4 in the ESI. $\dagger$ Inset: Picture of $0.1 \mathrm{M} \mathrm{Cu}($ II) extraction by thymol:capric acid HES (top phase) as a function of $\mathrm{pH}$ from 1 to 5 .

in HES. Although both HES present similar pH behaviour, the menthol-based HES was unstable over time at $\mathrm{pH}$ values over 4.9 and split into a $\mathrm{Cu}$ (II)-rich carboxylate phase and menthol crystals. No such behaviour was observed in the thymol-based HES which displays a higher ability to establish non-specific interactions with a solute due probably to thymol's aromaticity. ${ }^{10}$ Furthermore, a composition of $x_{\text {capric acid }}=0.7$ is close to the liquidus range limit of menthol-based HES at room temperature. ${ }^{10}$ The concentration of $\mathrm{Cu}$ (II) disturbs the (limited) hydrogen-bond network in the pure HES responsible for the lowering of the eutectic temperature. This leads to the splitting of the HES into a $\mathrm{Cu}(\mathrm{II})$-rich capric acid phase and menthol crystals.

The loading of $\mathrm{Cu}$ (II) was considered in order to evaluate the capacity of the HES phase and is presented in Fig. 3. $\mathrm{Cu}$ (II) extraction into menthol and thymol-based HES is high until $0.0075 \mathrm{M}$ after which a sharp decrease in extraction efficiency is

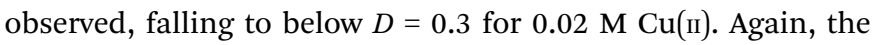
formation of a third phase appears in the saturated mentholbased HES at higher loading rates. As such, thymol:capric acid was the only HES considered for further experiments. A maximum loading rate of $0.64 \mathrm{~g} \mathrm{~L}^{-1}$ was achieved at the optimal conditions

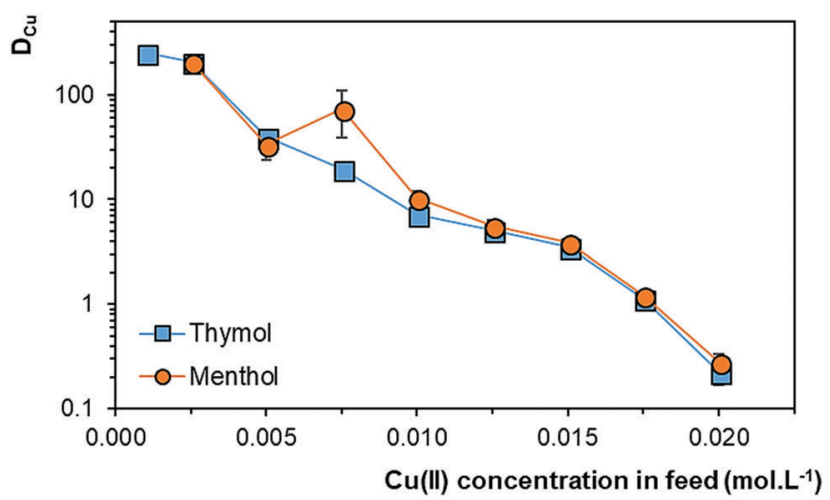

Fig. $3 \mathrm{Cu}(\Perp)$ distribution $\left(D_{\mathrm{Cu}}\right)$ as a function of initial $\mathrm{Cu}(॥)$ concentration in the aqueous solution ( $x_{\text {capric acid }}=0.7, T=20^{\circ} \mathrm{C}, \mathrm{pH}=4.9$ ). of $x_{\text {capric acid }}=0.7,0.1 \mathrm{M} \mathrm{Na}_{2} \mathrm{SO}_{4}$ and a $\mathrm{pH}$ of 4.9 . The viscosity of the HES remains low after extraction with $12 \mathrm{mPa} \mathrm{s}$ at $25{ }^{\circ} \mathrm{C}$ (Fig. S6 in the ESI $\dagger$ ), further validating its ease of handling.

The obtained loading for the thymol:capric acid HES is significantly lower than conventional carboxylic extractant loading but one order of magnitude higher than that obtained for indium extraction using a menthol:lauric acid HES. ${ }^{6}$ The nature of the salt additive was found to have an important impact on the loading of the HES phase (Fig. S7 in the ESI $\dagger$ ). The extraction efficiency increased $10 \%$ by changing from a simple $0.02 \mathrm{M} \mathrm{CuSO}_{4}$ solution, to one containing $0.02 \mathrm{M} \mathrm{CuSO}_{4}$ with $0.1 \mathrm{M} \mathrm{Na}_{2} \mathrm{SO}_{4}$ due to a salting-out phenomenon. Substituting $\mathrm{Na}_{2} \mathrm{SO}_{4}$ for its nitrate and chloride counterpart did not meaningfully improve $\mathrm{Cu}(\mathrm{II})$ extraction. However, quantitative $\mathrm{Cu}(\mathrm{II})$ extraction was achieved after adding $0.1 \mathrm{M}$ of sodium acetate, sodium maleate or sodium salicylate. The addition of carboxylate bearing ligands, either monocarboxylic or dicarboxylic and aliphatic or aromatic can drastically increase the loading of the HES. This is of interest for leaching applications employing organic acids. ${ }^{13}$

To ensure the viability of the hydrophobic eutectic solvent, the water content of the HES phase and ${ }^{1} \mathrm{H}$-NMR analysis of the aqueous phase after extraction were performed to quantify any losses of the HES constituents. The HES is highly hydrophobic, with the water content increasing from $0.15 \mathrm{wt} \%$ in the pure HES to only $2.50 \mathrm{wt} \%$ after extraction. Conversely, ${ }^{1} \mathrm{H}-\mathrm{NMR}$ analysis, presented in Fig. S8B in the ESI, $\dagger$ reveal no measurable loss of any of the HES to the aqueous phase in accordance with the negligible solubility of the HES component in water. ${ }^{10}$ Furthermore, the HES was shown to be recyclable over five extraction and stripping cycles with no appreciable loss in the extraction efficiency (Fig. S9 in the ESI $\dagger$ ). Stripping was performed using a $0.1 \mathrm{M} \mathrm{H}_{2} \mathrm{SO}_{4}$ solution. The ${ }^{1} \mathrm{H}$-NMR spectra of the recovered HES matches that of the original HES (Fig. S8A in the $\mathrm{ESI} \dagger$ ), indicating the complete recovery of the HES constituents, thereby maintaining the original thymol to capric acid molar ratio. Having successfully demonstrated the mechanisms of $\mathrm{Cu}$ (II) extraction in terpene:carboxylic acid HES and its recyclability, the partitioning of first row transition metals $(0.01 \mathrm{M})$ is studied. The results are presented in Fig. 4 and qualitatively illustrated in Fig. S10 of the ESI. $\dagger$

Of the presented metals, $\mathrm{Cu}(\mathrm{II})$ and $\mathrm{Fe}(\mathrm{III})$ could be successfully extracted whilst extraction of $\mathrm{Mg}$ (II), $\mathrm{Ca}(\mathrm{II}), \mathrm{Cr}(\mathrm{III}), \mathrm{Mn}$ (II), $\mathrm{Co}$ (II) and $\mathrm{Ni}$ (II) is negligible at the tested conditions, further widening the potential applicability of HES. Zn(II) presents an intermediate behaviour between that of $\mathrm{Cu}(\mathrm{II})$ and $\mathrm{Ni}(\mathrm{II})$. The extractability of metal ions in HES follows the general sequence observed for the solvent extraction of these metal cations with carboxylic acid ligands and ionic liquids bearing a carboxylic moiety on the cation. ${ }^{14,15}$ The ability of terpene-derived HES to mirror the extraction behaviour of their respective carboxylic acid constituent in solvent extraction expands the potential applicability of HES beyond the tested metals to other critical ones known to display a high affinity for carboxylates like $\operatorname{Pd}($ II) or In(III). ${ }^{15}$ By changing the nature of the carboxylic acid from fatty acids to bio-derived salicylates for example, HES can be 


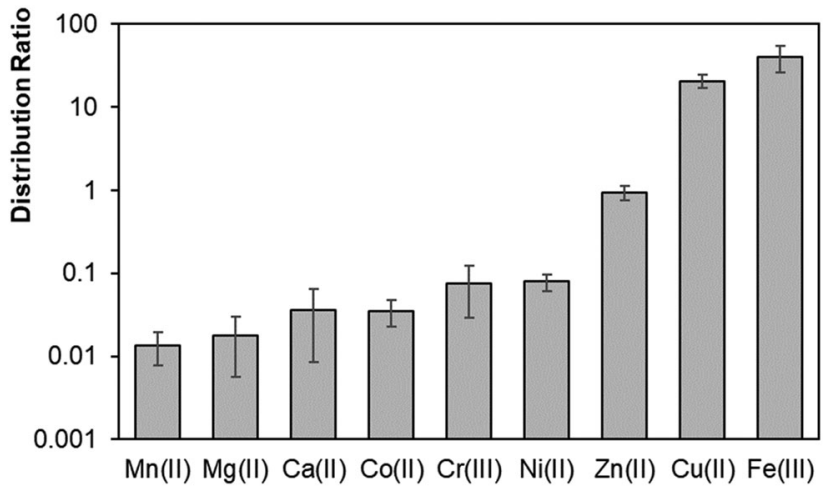

Fig. 4 Distribution ratio for the extraction of $0.01 \mathrm{M}$ transition metals, $\mathrm{Mg}(I)$ and $\mathrm{Ca}(॥)$ from sulfate media $\left(0.1 \mathrm{M} \mathrm{Na}_{2} \mathrm{SO}_{4}\right)$ by thymol:capric acid HES ( $x_{\text {capric acid }}=0.7, T=20{ }^{\circ} \mathrm{C}, \mathrm{pH}=4.9$ for divalent metals and $\mathrm{pH}=3.0$ for trivalent metals).

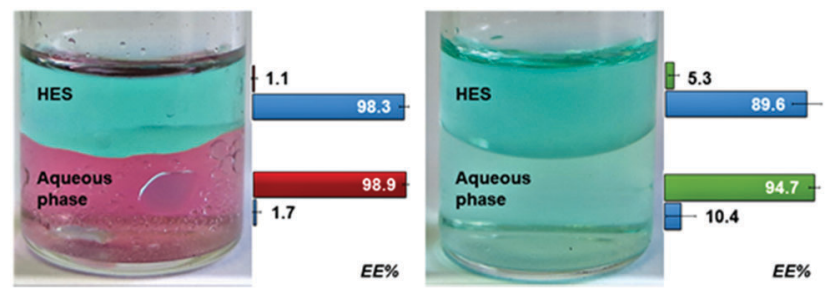

Fig. 5 Separation of $\mathrm{Cu}(\mathrm{II})(0.01 \mathrm{M}$, blue) from $0.1 \mathrm{M}$ solution of $\mathrm{Co}(\mathrm{II})(\mathrm{red})$ and $\mathrm{Ni}(\mathrm{II})$ (green) respectively in the thymol:capric acid HES ( $x_{\text {capric acid }}=0.7$, $T=20{ }^{\circ} \mathrm{C}, \mathrm{pH}=4.9$ ).

formulated for the selective extraction of specific metal ions. ${ }^{15}$ Additionally, based on the current industrial prices for capric acid $\left(2 € \mathrm{~kg}^{-1}\right)$, thymol and menthol $\left(10 € \mathrm{~kg}^{-1}\right)$, the proposed HES are competitively priced compared to ionic liquids. ${ }^{16}$ For a composition of $x_{\text {capric acid }}=0.7$, menthol- and thymol-based HES cost $4.2 € \mathrm{~kg}^{-1}$. In short, HES based on terpenes display the selectivity of traditional solvent extraction whilst eliminating the need for organic diluent, thereby making them a biodegradable, nontoxic and affordable alternative.

To further illustrate the high selectivity of the studied HES for $\mathrm{Cu}$ (II) compared to $\mathrm{Ni}$ (II) and $\mathrm{Co}$ (II), $0.01 \mathrm{M} \mathrm{Cu(II)}$ was extracted from concentrated $0.1 \mathrm{M} \mathrm{Co}(\mathrm{II})$ and $\mathrm{Ni}(\mathrm{II})$ solutions, respectively. The separation of $\mathrm{Cu}(\mathrm{II})$ from the divalent transition metals $\mathrm{Co}(\mathrm{II})$ and $\mathrm{Ni}(\mathrm{II})$ is investigated at the optimal conditions $\left(x_{\text {capric acid }}=0.7, \mathrm{pH}\right.$ of $4.9, T=20^{\circ} \mathrm{C}$ and O:A of 1$)$ and the results are presented in Fig. 5. An effective separation was obtained with a separation factor of over 500 and 154 for the $\mathrm{Cu}$ (II)/Co(II) and $\mathrm{Cu}(\mathrm{II}) / \mathrm{Ni}$ (II) pairs, respectively. The HES displays a greater selectivity for $\mathrm{Cu}(\mathrm{II})$ than quaternary ammonium ionic liquids containing fatty acid anions, which shown to extract the transition metals $\mathrm{Mn}$ (II), $\mathrm{Zn}$ (II), $\mathrm{Co}$ (II), Ni(II) and $\mathrm{Fe}(\mathrm{III})$ from chloride media. ${ }^{17}$

To conclude, this work represents the first proof of metal separation using a hydrophobic eutectic solvent composed of bio-sourced terpenes and fatty acids, opening new possibilities for HES application. Through careful evaluation of the hydrophobic eutectic composition, $\mathrm{Cu}$ (II) extraction was optimised by investigating the carboxylic acid chain length, the carboxylic acid mole fraction, the terpene selection and the effect of $\mathrm{pH}$ and salt addition. The resulting thymol:capric acid HES can separate $\mathrm{Cu}$ (II) with high selectivity from concentrated solutions containing other transition metals.

This work was part of BATRE-ARES project (ERA-MIN/0001/ 2015) funded by ADEME and FCT and partly developed in the scope of the project CICECO - Aveiro Institute of Materials, POCI-01-0145-FEDER-007679 (FCT Ref. UID/CTM/50011/2013). C. M. S. S. Neves acknowledges FCT for the postdoctoral grant (SFRH/BPD/109057/2015). M. A. R. Martins acknowledges financial support from NORTE 2020 (NORTE-01-0145-FEDER000006) and DeepBiorefinery (PTDC/AGRTEC/1191/2014) projects.

\section{Conflicts of interest}

There are no conflicts to declare.

\section{References}

1 F. O. Ongondo, I. D. Williams and T. J. Cherrett, Waste Manag., 2011, 31, 714-730.

2 European Commission, Report on critical raw materials for the EU. Brussels, 2014.

3 A. M. Wilson, P. J. Bailey, P. A. Tasker, J. R. Turkington, R. A. Grant and J. B. Love, Chem. Soc. Rev., 2014, 43, 123-134.

4 F. Pena-Pereira and J. Namieśnik, ChemSusChem, 2014, 7, 1784-1800; C. J. Clarke, W.-C. Tu, O. Levers, A. Bröhl and J. P. Hallett, Chem. Rev., 2018, 118, 747-800.

5 D. J. G. P. van Osch, D. Parmentier, C. H. J. T. Dietz, A. van den Bruinhorst, R. Tuinier and M. C. Kroon, Chem. Commun., 2016, 52, 11987-11990.

6 E. E. Tereshatov, M. Y. Boltoeva and C. M. Folden III, Green Chem., 2016, 18, 4616-4622.

7 B. D. Ribeiro, C. Florindo, L. C. Iff, M. A. Z. Coelho and I. M. Marrucho, ACS Sustainable Chem. Eng., 2015, 3, 2469-2477.

8 D. J. G. P. van Osch, L. F. Zubeir, A. van den Bruinhorst, M. A. A. Rocha and M. C. Kroon, Green Chem., 2015, 17, 4518-4521; J. Cao, M. Yang, F. Cao, J. Wang and E. Su, ACS Sustainable Chem. Eng., 2017, 5, 3270-3278; C. Florindo, L. Romero, I. Rintoul, L. C. Branco and I. M. Marrucho, ACS Sustainable Chem. Eng., 2018, 6, 3888-3895; R. Verma and T. Banerjee, Ind. Eng. Chem. Res., 2018, 57, 3371-3381.

9 M. Francisco, A. van den Bruinhorst and M. C. Kroon, Angew. Chem., Int. Ed., 2013, 52, 3074-3085.

10 M. A. R. Martins, E. A. Crespo, P. V. A. Pontes, L. P. Silva, M. Bülow, G. J. Maximo, E. A. C. Batista, C. Held, S. P. Pinho and J. A. P. Coutinho, ACS Sustainable Chem. Eng., 2018, DOI: 10.1021/ acssuschemeng.8b01203.

11 M. Kyuzou, W. Mori and J. Tanaka, Inorg. Chim. Acta, 2010, 363, 930-934.

12 K. Inoue, H. Amano and I. Nakamori, Hydrometallurgy, 1982, 8, 309-329.

13 L. Li, E. Fan, Y. Guan, X. Zhang, Q. Xue, L. Wei, F. Wu and R. Chen, ACS Sustainable Chem. Eng., 2017, 5, 5224-5233; F.-J. Albler, K. Bica, M. R. StJ. Foreman, S. Holgersson and M. S. Tyumentsev, J. Cleaner Prod., 2017, 167, 806-814.

14 R. M. Smith and A. E. Martell, Sci. Total Environ., 1987, 64, 125-147; F. M. Doyle, D. Pouillon and E. A. Villegas, Hydrometallurgy, 1988, 19, 289-308; T. Vander Hoogerstraete, B. Onghena and K. Binnemans, J. Phys. Chem. Lett., 2013, 4, 1659-1663.

15 J. S. Preston, Hydrometallurgy, 1985, 14, 171-188; J. Rydberg and Y. Albinsson, Solvent Extr. Ion Exch., 1989, 7, 577-612.

16 Alibaba $^{\circledR}$, https://www.alibaba.com/, accessed: 18/06/18.

17 D. Parmentier, T. Vander Hoogerstraete, D. Banerjee, Y. A. Valia, S. J. Metz, K. Binnemans and M. C. Kroon, Dalton Trans., 2016, 45, 9661-9668. 